\title{
Relation of basal coronary tone and vasospastic activity in patients with variant angina
}

\author{
Yukio Ozaki, David Keane, Patrick W Serruys
}

\begin{abstract}
Objective-To examine the vasoconstrictor response to ergonovine and the vasodilator response to isosorbide dinitrate in spastic and non-spastic coronary segments from 31 patients undergoing serial angiographic follow up of variant angina.
\end{abstract}

Methods-Coronary angiograms and ergonovine provocation tests were repeated at an interval of 45 (SD 15) months apart. While all 31 patients showed a positive response to ergonovine initially, vasospastic responsiveness persisted in only 16 patients at follow up (group 1) and not in the other 15 patients in whom symptoms of variant angina had resolved (group 2). Mean luminal diameter of 170 normal or near normal entire coronary segments (American Heart Association classification) were measured (a) at baseline, (b) after the administration of ergonovine, and (c) after the administration of isosorbide dinitrate, during both the initial and follow up angiograms using a computer based quantitative angiography analysis system (CAAS II).

Results-In vasospastic patients (initial and follow up angiograms in group 1, and initial angiogram in group 2), basal tone was significantly higher in spastic segments compared to adjacent segments or segments in non-spastic vessels. The diagnostic sensitivity and specificity at $20 \%$ increase in basal coronary tone for the prediction of vasospasm were $77 \%$ and $73 \%$, respectively.

Conclusions-Coronary artery tone may change in proportion to the activity of variant angina over several years. Contrary to some previous reports, the estimation of basal coronary tone may be useful in the assessment of vasospastic activity in patients with variant angina.

(Heart 1996;75:267-273)

Keywords: coronary spasm, variant angina, ergonovine provocation test, quantitative coronary angiography

Coronary vasospasticity plays an integral role in the genesis of variant angina, some types of acute myocardial infarction, and restenosis after balloon angioplasty. ${ }^{1-9}$ The proposed mechanism of vasospasm includes hypersensitivity to endothelium derived factors, platelet derived vasoactive substances, and autonomic nervous tone. ${ }^{10-13}$ Basal coronary tone is felt to be related to the regulation of vascular smooth muscle tension by local endothelium derived factors, humoral factors, and parasympathetic nervous tone. ${ }^{14-16}$ Thus similar factors may play a role in both vasospasm and the mediation of basal coronary tone. Despite the common mediators, previous clinical studies attempting to determine whether basal coronary tone is increased in patients with vasospastic angina have yielded conflicting evidence ${ }^{17-22}$ and the chronological interaction of basal coronary tone and vasospastic activity over several years is unknown.

To examine the role of coronary tone, its chronological changes, and its relation to vasospastic anginal attacks, we compared basal coronary tone and vasospastic activity during both initial and follow up angiographic studies in 31 patients. We measured changes in mean luminal diameter of each entire spastic segment, segments adjacent to the spastic segment, and segments in non-spastic vessels at baseline, after administration of ergonovine and after administration of isosorbide dinitrate, using computer based quantitative coronary angiography.

\section{Methods}

PATIENT SELECTION

Thirty one patients who met the following criteria of variant angina were included in the study: (1) chest pain at rest associated with ST segment changes of more than $0.2 \mathrm{mV}$ on ECG; (2) pain relief immediately following the administration of glyceryl trinitrate; (3) no subsequent evidence of myocardial infarction; and (4) ergonovine provoked coronary spasm associated with chest pain and ischaemic ECG changes. Coronary spasm was defined as a transient total or nearly total occlusion reversible with isosorbide dinitrate, or as a transient but significant $(>50 \%)$ narrowing reversible with isosorbide dinitrate in normal or nearly normal segments. ${ }^{82324}$

The disease activity of vasospastic angina was assessed by anginal symptoms, 12-lead ECG during symptoms, and ambulatory inhospital electrocardiographic monitoring, or Holter monitoring out of hospital. Of the 31 patients who had symptoms of variant angina at the time of the initial angiographic study, 16 
had persistent symptoms of vasospastic angina with ischaemic electrocardiographic changes during the follow up period, and vasospasm was reproduced at the same coronary site at the follow up angiogram (group 1), while in 15 patients symptoms of variant angina had resolved completely and neither ischaemic ST segment changes nor positive response to ergonovine was demonstrated during follow up (group 2).

Table 1 shows the clinical and electrocardiographic characteristics of the two groups. There were no significant differences in age, gender, duration of follow up, coronary risk factors, or location of ischaemic ST segment changes on ECG. One patient of each group with ST elevation in both anterior and inferior leads had spasm in the right coronary and left anterior descending coronary arteries.

It has been reported that the response to an ergonovine provocation test is of value in the prediction of spontaneous activity of vasospastic angina..$^{25} \mathrm{We}$ therefore performed follow up angiography and ergonovine provocation testing when progression of coronary atherosclerosis was suspected, frequency of anginal attacks increased, or vasospastic activity was thought to have resolved, and it may no longer have been necessary to continue long term drug treatment. In patients who had a negative response to ergonovine at the follow up test (group 2) the treatment dose was tapered or discontinued after the follow up angiogram. At angiographic follow up, coronary spasm was observed at the same coronary arterial site in group 1 , while no spasm was reproduced at follow up in group 2.

STUDY PROTOCOL

The study was approved by the hospital's ethics committee and informed written consent was obtained from each patient before examination. All patients were admitted to the coronary care unit before the study. Sublingual glyceryl trinitrate was given as required, but calcium antagonists and oral nitrates were gradually tapered, and calcium antagonists were discontinued for $36 \mathrm{~h}$ and oral nitrate was discontinued for $24 \mathrm{~h}$ before the study. Coronary angiography was performed in the morning (from 8:30 to 11:00 am) by the Sones technique at Anjo Kosei Hospital in Japan.

After baseline angiograms suitable for quantitative analysis of the right and left coronary arteries had been obtained, $0.2 \mathrm{mg}$ ergonovine

Table 1 Baseline characteristics of 31 patients with vasospastic angina in groups 1 and 2

\begin{tabular}{llll}
\hline & Group 1 & Group 2 & p value \\
\hline Number of patients & 16 & 15 & \\
Age, years (SD) & $55(8)$ & $55(12)$ & NS \\
Male/female & $15 / 1$ & $14 / 1$ & NS \\
Follow up period, months (SD) & $45(15)$ & $45(18)$ & NS \\
Coronary risk factors (No of patients) & & 3 & NS \\
$\quad$ Hypertension & 2 & 1 & NS \\
Hypercholesterolaemia & 1 & 1 & NS \\
$\quad$ Diabetes & 1 & 13 & NS \\
Smoking & 15 & 6 & NS \\
Site of ST elevation & 3 & 8 & NS \\
$\quad$ Anterior & 12 & 1 & NS \\
$\quad$ Inferior & 1 & & \\
Both & & &
\end{tabular}

maleate was given intravenously by a rapid bolus injection. Radiographic projections were identical during the sequential angiographic studies. Heart rate and aortic pressure were monitored continuously, and 12-lead ECGs were recorded at $30 \mathrm{~s}$ intervals. Whenever chest pain or significant ST segment changes were observed, selective coronary angiograms were immediately performed. In patients of group 2 at follow up, unresponsiveness to ergonovine was confirmed by the administration of a further rapid bolus of up to $0.4 \mathrm{mg}$ ergonovine. In group 1 at both tests and group 2 at the initial test, all coronary spasms were observed after the first administrated dose of ergonovine $(0.2 \mathrm{mg})$.

Coronary vasospasm was relieved by isosorbide dinitrate, given as one or two intracoronary boluses to a total of $5 \mathrm{mg}$. To exclude the possibility of persistent spasm, we gave a dose $(5 \mathrm{mg}$ ) of intracoronary isosorbide dinitrate which was greater than the dose previously shown to achieve maximum coronary vasodilatation in patients with vasospastic angina (3 mg). ${ }^{27} 28$

The follow up angiography and provocation tests were performed in the same angiographic projection as the initial angiogram after viewing the initial angiographic records and cinefilm. The response to ergonovine and isosorbide dinitrate and the severity of fixed stenosis after the administration of isosorbide dinitrate were quantified in matched views between the initial and follow up angiograms using a quantitative angiographic analysis system.

\section{QUANTITATIVE CORONARY ANGIOGRAPHIC} ANALYSIS

The new version of the computer based Coronary Angiography Analysis System (CAAS II) ${ }^{29}$ was used to perform the quantitative analysis in a core angiographic laboratory (Cardialysis, Rotterdam, The Netherlands). In the CAAS analysis, which has been described elsewhere previously, ${ }^{29-33}$ the entire cineframe of size $18 \times 24 \mathrm{~mm}$ is digitised at a resolution of $1329 \times 1772$ pixels. Correction for pincushion distortion is performed before analysis. Boundaries of a selected coronary segment are detected automatically. The absolute diameter of the stenosis (in $\mathrm{mm}$ ) is determined using the guiding catheter as a scaling device. To standardise the method of analysis of the initial and follow up angiograms, the following measures were taken ${ }^{34}$ : all study frames selected for analysis were end diastolic to minimise motion artefact; and arterial segments were measured between the same identifiable branch points at baseline, after the administration of ergonovine, and after the administration of isosorbide dinitrate. Changes in the mean luminal diameter of each entire coronary segment as well as the minimum luminal diameter of each analysed coronary segment were studied.

ANALYSED SEGMENTS

In group 1, the 16 spastic segments studied were located in the right coronary artery 
(RCA) in eight patients, left anterior descending coronary artery (LAD) in two patients, and left circumflex coronary artery (LCX) in six patients. In group 2 , the 16 spastic segments were located in the RCA in eight patients, the LAD in six patients, and the LCX in two patients. The three major coronary arteries were divided according to the classification of the American Heart Association (AHA) committee report. ${ }^{35}$ The proximal and distal segments of each coronary artery were analysed. The proximal segment of the RCA was taken as AHA segments 1 and 2, the distal segment of the RCA was AHA segment 3, the proximal segment of the LAD was AHA segment 6, the distal segment was AHA segment 7, the proximal segment of the LCX was AHA segment 11, and the distal segment was AHA segment 13.

For the purpose of this study only angiographically normal or nearly normal segments were selected. Of a total of 93 major coronary arteries in both groups, four vessels in each group with a significant stenosis ( $>50 \%$ diameter stenosis) were excluded from analysis. ${ }^{21}$ Sixteen spastic AHA segments, 16 AHA segments adjacent to spastic segments (adjacent segment), and 56 segments in non-spastic vessels were estimated in group $1 ; 16$ spastic AHA segments, 16 segments adjacent to spastic segments, and 50 segments in non-spastic vessels were assessed in group 2.

\section{ESTIMATION OF BASAL CORONARY TONE AND VASOCONSTRICTION}

Basal coronary tone and vasoconstriction were determined from the change in the mean luminal diameter of each entire AHA coronary segment at baseline, after the administration of ergonovine, and after the administration of isosorbide dinitrate. To express the degree of basal coronary artery tone and the degree of vasoconstriction, ${ }^{171921}$ the per cent dilatation after administration of isosorbide dinitrate and per cent vasoconstriction after administration of ergonovine were used as follows:

Basal coronary tone (dilatation after isosorbide dinitrate) $(\%)=$

(Mean luminal diameter after isosorbide dinitrate baseline mean luminal diameter $) \times 100$

Baseline mean luminal diameter

Constriction after ergonovine (\%) =

(Baseline mean luminal diameter - mean luminal diameter after ergonovine) $\times 100$

Baseline mean luminal diameter
DIAGNOSTIC PREDICTIVE VALUES OF BASAL TONE FOR VASOSPASM IN CORONARY ARTERY

The diagnostic sensitivity and specificity were defined as follows ${ }^{22}$ :

Diagnostic sensitivity $(\%)=$

$$
\frac{\text { True positive } \times 100}{\text { True positive }+ \text { false negative }}
$$

Diagnostic specificity $(\%)=$

$$
\frac{\text { True negative } \times 100}{\text { True negative }+ \text { false positive }}
$$

While the true positive value indicates the number of spastic segments in spastic vessel which show basal coronary tone above a value of coronary tone, the false negative value indicates the number of spastic segments in spastic vessel which show basal coronary tone below the same value. While the true negative value indicates the number of non-spastic segments in non-spastic vessel which show basal coronary tone below a value of coronary tone, the false positive value indicates the number of non-spastic segments in non-spastic vessel which show basal coronary tone above the same value.

\section{STATISTICAL ANALYSIS}

All values are expressed as mean (SEM). The paired Student $t$ test was used to compare the chronological changes at the same segment in the same patients. The unpaired Student $t$ test was used to compare different segments or different patient groups. Differences between proportions were analysed by the $\chi^{2}$ test with correction. A P value of less than 0.05 was considered significant.

\section{Results}

RESPONSE TO ERGONOVINE AT THE SPASTIC SITE

Coronary spasm was observed at the same site in group 1 , while no spasm was reproduced at follow up in group 2 . In group 1 , the absolute reduction in the minimum luminal diameter in the spastic segment was 1.21 (SEM 0.09) $\mathrm{mm}$ with a reduction in minimum diameter of 70 (5)\% during the initial angiogram and $1.05(0.09) \mathrm{mm}$ [68 (5)\% reduction] at follow up; in group 2 , the reduction in minimum luminal diameter was $1.04(0.09) \mathrm{mm}[69(5) \%$ reduction] during the initial angiogram and 0.32

\begin{tabular}{|c|c|c|c|c|c|c|}
\hline & \multicolumn{3}{|c|}{ Initial angiogram } & \multicolumn{3}{|c|}{ Follow up angiogram } \\
\hline & Baseline ( $\mathrm{mm}$ ) & After ergonovine $(\mathrm{mm})$ & Reduction (\%) & Baseline ( $\mathrm{mm}$ ) & After ergonovine ( $\mathrm{mm}$ ) & Reduction (\%) \\
\hline $\begin{array}{l}\text { Group } 1 \\
\text { Spastic segment } \\
\text { Adjacent to spastic segment } \\
\text { Segment of non-spastic vessel }\end{array}$ & $\begin{array}{l}2 \cdot 14(0.10) \\
2 \cdot 28(0.09) \\
2 \cdot 61(0.07)\end{array}$ & $\begin{array}{l}1.56(0.08) \\
1.90(0.09) \\
2.20(0.07)\end{array}$ & $\begin{array}{l}27(3) \\
17(2) \\
15(1)\end{array}$ & $\begin{array}{l}2 \cdot 00(0 \cdot 12) \\
2 \cdot 21(0.10) \\
2 \cdot 58(0.08)\end{array}$ & $\begin{array}{l}1.48(0.10) \\
1.93(0.11) \\
2.22(0.08)\end{array}$ & $\begin{array}{l}26(2) \\
17(2) \\
14(1)\end{array}$ \\
\hline $\begin{array}{l}\text { Group } 2 \\
\text { Spastic segment } \\
\text { Adjacent to spastic segment } \\
\text { Segment of non-spastic vessel }\end{array}$ & $\begin{array}{l}2.07(0.12) \\
2 \cdot 22(0 \cdot 10) \\
2 \cdot 52(0.07)\end{array}$ & $\begin{array}{l}1.46(0.09) \\
1.84(0.10) \\
2 \cdot 18(0.07)\end{array}$ & $\begin{array}{l}29(3) \\
16(1) \\
14(1)\end{array}$ & $\begin{array}{l}2.45(0.11) \\
2.49(0.12) \\
2.54(0.06)\end{array}$ & $\begin{array}{l}2.09(0.08) \\
2.11(0.10) \\
2.22(0.06)\end{array}$ & $\begin{array}{l}13(3) \\
14(3) \\
13(1)\end{array}$ \\
\hline
\end{tabular}
$(0.07) \mathrm{mm}$ [15 (3)\% reduction] at follow up.

Table 2 Mean diameter of coronary artery segment and response to ergonovine during initial and follow up angiograms in groups 1 and 2 . Values are means (SEM)

Adjacent to spastic segment, segments either proximal or distal to the spastic segment. 
Table 3 Mean diameter of coronary artery segment and response to isosorbide dinitrate during initial and follow up angiograms in groups 1 and 2. Values are means (SEM)

\begin{tabular}{|c|c|c|c|c|c|c|}
\hline & \multicolumn{3}{|l|}{ Initial angiogram } & \multicolumn{3}{|c|}{ Follow up angiogram } \\
\hline & Baseline $(\mathrm{mm})$ & $\begin{array}{l}\text { After isosorbide } \\
\text { dinitrate }(\mathrm{mm})\end{array}$ & Dilatation $(\%)$ & Baseline ( $\mathrm{mm}$ ) & $\begin{array}{l}\text { After isosorbide } \\
\text { dinitrate }(\mathrm{mm})\end{array}$ & Dilatation $(\%)$ \\
\hline \multicolumn{7}{|l|}{ Group 1} \\
\hline Spastic segment & $2 \cdot 14(0 \cdot 10)$ & $2 \cdot 84(0 \cdot 14)$ & $33(4)$ & $2 \cdot 00(0 \cdot 12)$ & $2.65(0.13)$ & $35(4)$ \\
\hline Adjacent to spastic segment & $2.28(0.09)$ & $2 \cdot 78(0 \cdot 10)$ & $23(2)$ & $2 \cdot 21(0 \cdot 10)$ & $2 \cdot 74(0 \cdot 12)$ & $24(2)$ \\
\hline Segment of non-spastic vessel & $2.61(0.07)$ & $3.02(0.07)$ & $16(1)$ & $2.58(0.08)$ & $2.98(0.08)$ & $16(1)$ \\
\hline \multicolumn{7}{|l|}{ Group 2} \\
\hline Spastic segment & $2.07(0.12)$ & $2 \cdot 80(0 \cdot 18)$ & $35(4)$ & $2 \cdot 45(0 \cdot 11)$ & $2 \cdot 81(0 \cdot 15)$ & $15(3)$ \\
\hline Adjacent to spastic segment & $2 \cdot 22(0 \cdot 10)$ & $2.73(0 \cdot 16)$ & $23(4)$ & $2.49(0 \cdot 12)$ & $2.83(0 \cdot 16)$ & $14(3)$ \\
\hline Segment of non-spastic vessel & $2.52(0 \cdot 07)$ & $2.87(0.08)$ & $15(1)$ & $2 \cdot 54(0.06)$ & $2.90(0.07)$ & $15(1)$ \\
\hline
\end{tabular}

Adjacent to spastic segment, segments either proximal or distal to the spastic segment.

VASOMOTOR BEHAVIOUR OF THE SEGMENTS AT THE INITIAL. AND FOLLOW UP TESTS

Table 2 shows the average values of mean luminal diameter of each spastic segment, of the adjacent segments, and of segments of non-spastic vessels at baseline and after administration of ergonovine, and the per cent vasoconstriction, in groups 1 and 2 . Table 3 gives the average value of the mean luminal diameter at baseline and after administration of isosorbide dinitrate, and the per cent dilatation (basal coronary tone) in groups 1 and 2 .

\section{Group 1}

Figure 1 shows the vasoconstriction and basal coronary tone in group 1. Vasoconstriction of the spastic segment was greater than that of the adjacent segment or of segments in nonspastic vessels during the initial and follow up tests. Basal coronary tone in the spastic segments was also greater than in the adjacent segments or in segments of non-spastic vessels during the initial and follow up tests. No significant difference between the initial and follow up tests was found in either vasoconstriction or basal tone in any of the spastic or adjacent segments or the segments in non-

Figure 1 Group 1

Vasomotor responses to

ergonovine (constriction) and isosorbide dinitrate (basal tone) in spastic segments (black bar), adjacent segments (hatched bar), and segments in nonspastic vessels (white bar) of patients in group 1 at the initial and follow up angiograms.

Vasoconstriction and basal coronary tone in the three segments were similar between the initial and follow up tests. Error bar indicates 1 SEM.

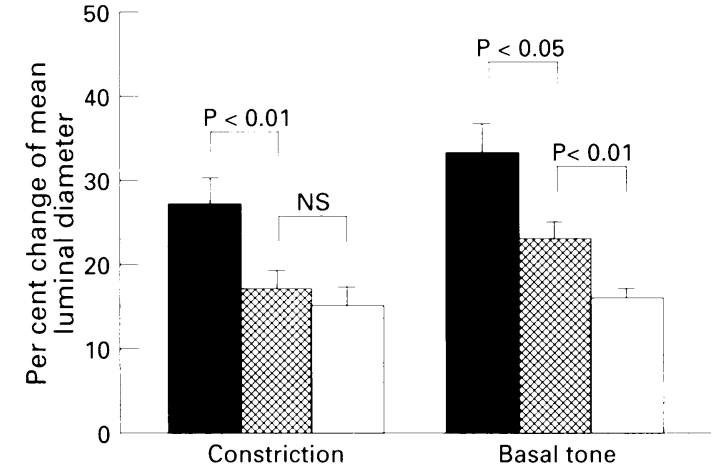

Initial test

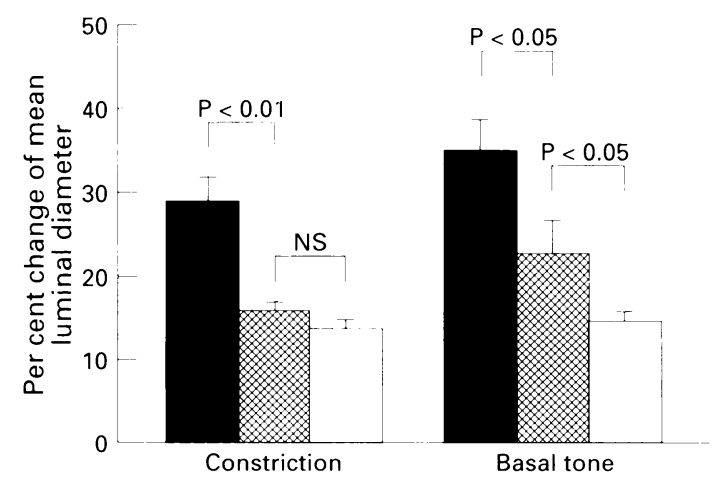

Follow up test

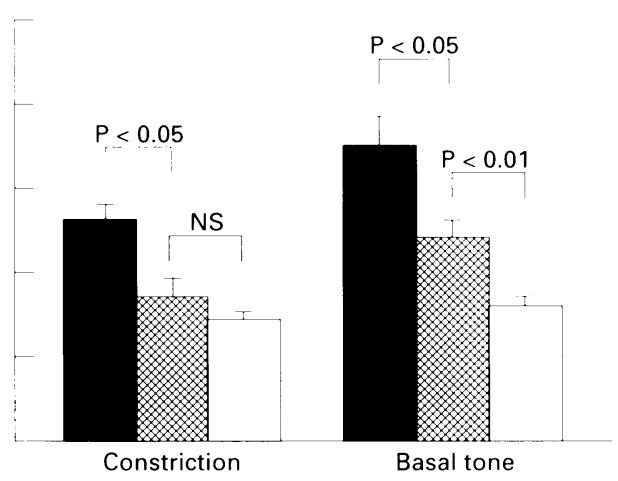

Follow up test

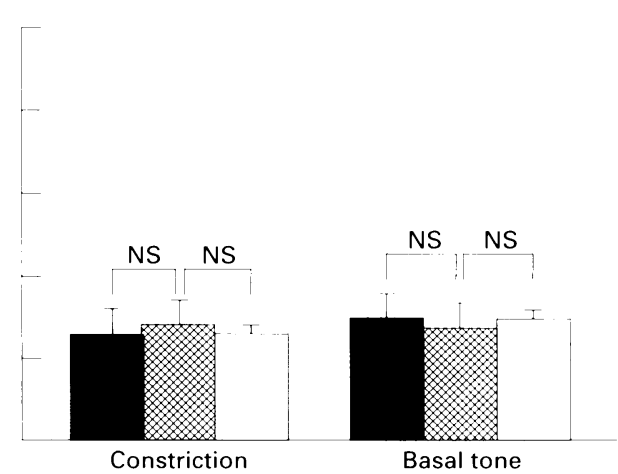

Figure 2 Group 2: Vasomotor responses to ergonovine (constriction) and isosorbide dinitrate (basal tone) in spastic segments (black bar), adjacent segments (hatched bar), and segments in non-spastic vessels (white bar) of patients in group 2 at the initial and follow up angiograms. Vasoconstriction and basal coronary tone in the spastic segments decreased significantly from the initial to the follow up tests. Basal tone of the adjacent segments also decreased from the initial to the follow up test, while vasoconstriction of the adjacent segments was unchanged (NS). Segments in non-spastic vessels showed similar vasoconstriction and basal coronary tone at both tests (NS). Error bar indicates 1 SEM. 


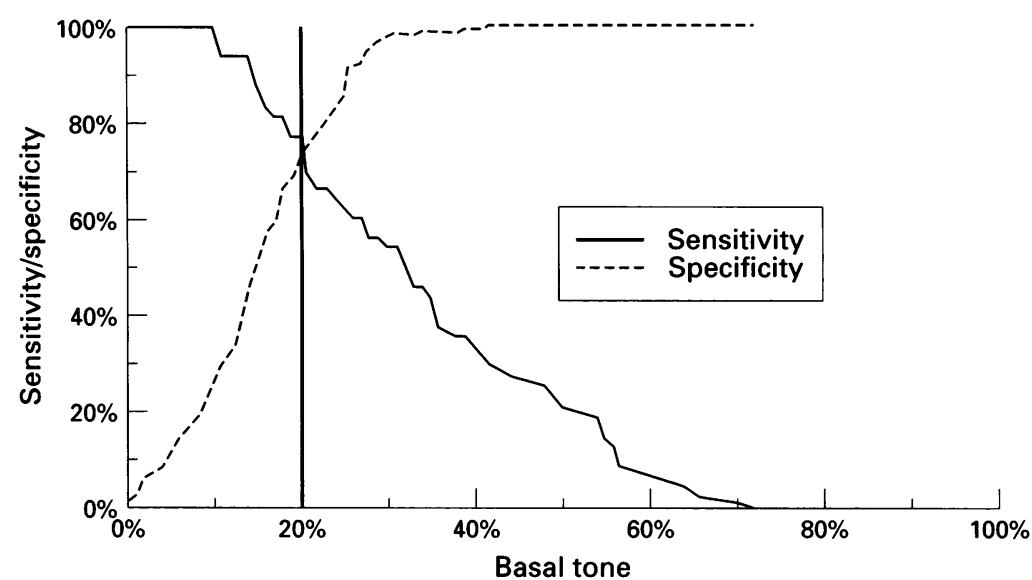

Figure 3 Distribution curves of sensitivity and specificity of increased basal coronary tone for the prediction of vasospasm in a coronary artery. At a $20 \%$ increase in basal coronary tone (thick vertical line), which is the nearest rounded number to the crossing point of the two distribution curves, the sensitivity was $77 \%$ and the specificity $73 \%$.

spastic vessels. Although vasoconstriction in the adjacent segments was not significantly different from the vasoconstriction in segments of non-spastic vessels, basal tone in the adjacent segment was greater than that of segments in non-spastic vessels during both the initial and follow up tests.

Group 2

Figure 2 shows the vasoconstriction and basal coronary tone in group 2. During the initial test, vasoconstriction of the spastic segments was greater than in the adjacent segments or in segments in non-spastic vessels. During the initial test, vasoconstriction was comparable in adjacent segment and non-spastic segments, while basal coronary tone in the spastic segment was greater than in the adjacent segments and in the segments of non-spastic vessels. Furthermore, during the initial test, basal tone in the adjacent segments was greater than in the segments of non-spastic vessels. At follow up, no difference was observed in either vasoconstriction or basal tone among previously spastic and adjacent segments and segments in non-spastic vessels. Both vasoconstriction and basal coronary tone of the spastic segments decreased significantly from the initial to the follow up angiograms. Basal tone of the adjacent segments also decreased significantly from the initial to the follow up angiograms. Vasoconstriction of the adjacent segment was similar during the initial and follow up angiograms. We found no difference in vasoconstriction and basal tone of segments in non-spastic vessels between the initial and follow up angiograms

PREDICTIVE VALUE OF BASAL TONE FOR THE PRESENCE OF VASOSPASM

Figure 3 shows distribution curves of the sensitivity and specificity of basal coronary tone for the prediction of vasospasm in coronary artery. The sensitivity and specificity were calculated from all 48 spastic segments in spastic vessels and all 162 non-spastic segments in non-spastic vessels in the initial and follow up angiograms of group 1 and the initial angiogram of group 2. At $20 \%$ increase in basal tone, which is the nearest rounded number to the crossing point of two distribution curves, the sensitivity was $77 \%$ and specificity $73 \%$.

\section{Discussion}

The specific findings of this study are as follows: (1) neither basal coronary tone nor vasoconstriction changed over time in patients with persistent variant angina, while in patients in whom symptoms of variant angina resolved, both vasoconstriction and basal coronary tone of previously spastic segments were restored to normal; (2) vasoconstriction in adjacent segments and segments in nonspastic vessels was equivalent both in patients with active disease and in patients with inactive disease; (3) in patients with active disease, basal tone in spastic segments was greater than in adjacent segments or segments in non-spastic vessels; (4) adjacent segments only showed increased basal coronary tone compared to segments in non-spastic vessels during the period of disease activity.

\section{DISCORDANT FINDINGS OF PREVIOUS STUDIES}

Previous studies have provided conflicting evidence on whether basal coronary tone is increased in spastic segments. ${ }^{17-22}$ Hill et al reported that basal coronary tone in the spastic site, estimated after the administration of 0.4 $\mathrm{mg}$ of sublingual glyceryl trinitrate, was greater than in non-spastic sites in 17 patients with variant angina. ${ }^{17}$ Hoshino et al reported that coronary artery tone assessed after the administration of $5 \mathrm{mg}$ intraaortic isosorbide dinitrate was greater in the entire coronary tree in 30 patients with variant angina than in 35 patients without coronary spasm. ${ }^{19}$ Hackett et $a l$, however, found that basal coronary tone, analysed after the administration of $2 \mathrm{mg}$ intracoronary isosorbide dinitrate, was not different at spastic sites than at non-spastic sites in six patients with variant angina. ${ }^{18}$ Kaski et al also found that basal coronary tone of segments in non-spastic vessels, estimated after the administration of 1 to $2 \mathrm{mg}$ intracoronary isosorbide dinitrate, was not different between 13 patients with variant angina and 41 patients without coronary spasm. ${ }^{21}$ Kuga et al found that basal coronary tone was increased in 15 patients with variant angina but not in five others after the administration of $0.26 \mathrm{mg}$ intravenous glyceryl trinitrate. ${ }^{22}$

The conflicting results of previous studies may relate to differences in patient selection and the methods employed, including (1) use of nitrates, (2) selection of angiographic segments, and (3) disease activity:

\section{Use of nitrates}

Although in all previous studies basal coronary tone was determined by the magnitude of vasodilator response to organic nitrates, there are differences in the dose and route of administration of nitrates (intracoronary or sublingual) in previous studies. In 1982, Lablanche et al found that maximum vasodilatation was achieved in patients with variant angina by 3 $\mathrm{mg}$ of intracoronary isosorbide dinitrate. ${ }^{27} 28$ 
However, we have found that further vasodilatation may be achieved in some patients by doubling the dose of isosorbide dinitrate from $2.5 \mathrm{mg}$ to $5.0 \mathrm{mg}$. With the aim of achieving maximal vasodilatation in all our study population we estimated coronary artery diameter after the intracoronary administration of $5 \mathrm{mg}$ isosorbide dinitrate. While Feldman et al ${ }^{36}$ reported that $0.4 \mathrm{mg}$ of sublingual glyceryl trinitrate evoked maximum coronary vasodilatation, Jost $e t a l^{37}$ recently found that $0.8 \mathrm{mg}$ was necessary to achieve maximum vasodilatation. Varying dosages and routes of administration of isosorbide dinitrate or glyceryl trinitrate as detailed above may have contributed to the different degree of vasomotor reposes observed in previous studies.

\section{Selection of angiographic segments}

The degree of vasodilatation following the administration of nitrates will not necessarily be identical at all points within a coronary segment (as evidenced by the difference in our results between changes at the spastic point and changes in the entire AHA segment with spasm). In some studies the vasomotor responses were measured at specific points of bifurcation, ${ }^{19}$ while we feel that change in the mean luminal diameter of each entire AHA coronary segment is of greater relevance for the assessment of coronary tone. Such differences in the selection of quantitative angiographic sites may add to the discrepancies of the results of previous studies.

\section{Disease activity}

The results of our study indicate that basal coronary tone changes in relation to changes in activity of vasospastic disease. Kuga et $a^{22}$ recently reported that basal coronary artery tone was increased at the spastic site when spasm was provoked by a low dose of ergonovine, whereas basal tone was not increased at those spastic sites that required a higher dose of ergonovine to induce spasm. Previtali et $a l^{26}$ indicated that a low dose of ergonovine was required in patients with a high degree of vasospastic angina, while in patients with low level of disease activity a high dose of ergonovine was necessary to provoke spasm. Thus the inverse relation between the dose of ergonovine required to provoke spasm and the degree of basal coronary tone may indirectly support our findings. Given the close relation between disease activity and vasomotor response, it is conceivable that differences in the state of disease activity in the patients of previous studies may have contributed to the discrepancies of their results.

\section{PATHOPHYSIOLOGICAL ROLE OF BASAL}

CORONARY TONE IN VASOSPASM

Experimental studies have indicated that various endothelium dependent vasoactive factors which modulate vascular smooth muscle contraction may play an important role. ${ }^{10-12}$ Waters et $a l^{38}$ and Kaski et $a l^{39}$ have shown that coronary spasm may be induced by several stimuli such as ergonovine, histamine, hyperventilation, and exercise in the same patient with variant angina and have suggested that vasospasm is caused by a variety of nonspecific stimuli. Basal coronary artery tone is thought to be mediated by a balance of various stimuli such as the parasympathetic nervous system, humoral factors, and local endothelium dependent vasoactive factors. ${ }^{14-16}$ Given the above similarities in mediation of coronary spasm and mediation of coronary tone, the demonstration of a close relation between coronary vasospastic disease and basal coronary vessel tone is not surprising. It could be hypothesised that basal coronary tone may express a "threshold" for vasospastic activity. Increased tone not in only spastic segments but also in adjacent segments may reflect a low "threshold" for vasospasm during high activity of the disease

\section{CONCLUSIONS}

Coronary artery tone may change in proportion to the activity of vasospastic disease over time. While vasoconstrictor response to ergonovine is increased in spastic segments only, basal tone of both spastic and adjacent segments is augmented during periods of active disease and is restored to normal during disease inactivity. The high diagnostic sensitivity and specificity of basal tone for prediction of spasm in coronary arteries indicates that the estimation of basal coronary tone may be useful in the assessment of vasospastic activity in patients with variant angina.

We gratefully acknowledge the dedication and contribution of Dr Fumimaro Takatsu, Dr Yukio Shiga, Dr Masato Watarai, Dr Seiji Shimizu, Dr Atsusi Nishiyama, Mr Takesi Suba, and all the staff of the catheterisation laboratory at Anjo Kose Hospital, Japan. In addition we are grateful to the staff of the Core Angiographic Laboratory, Cardialysis, in Rotterdam for their quantitative analysis of the coronary angiograms. We thank Eric Boersma MSc for his statistical advice. Dr Yukio Ozaki is a recipient of a grant from Takeda Medical Research (Taisha Ijo) Foundation, Osaka, Japan. Dr David Keane is recipient of a travel grant from the Peel Medical Research Trust, London, UK.

1 Maseri A, L'Abbate A, Persola A, et al. Coronary vasospasm in angina pectoris. Lancet 1977;i:713-8.

2 Maseri A, L'Abbate A, Baroldi G, et al. Coronary vasospasm as a possible cause of myocardial infarction: a conclusion derived from the study of "preinfarction" angina. N Engl f Med 1978;299:1271-7.

3 Bertrand ME, Lablanche JM, Tilmant PY, et al. Frequency of provoked coronary arterial spasm in 1089 consecutive patients undergoing coronary arteriography. Circulation 1982;65:1299-306.

4 Conti CR, Feldman RL, Pepine CJ. Coronary artery spasm: prevalence, clinical significance, and provocative testing. Am Heart f 1982;103:584-8.

5 Waters DD, Szlacheic J, Miller D, Theroux P. Clinica characteristics of patients with variant angina complicated by myocardial infarction or death within 1 month. Am $₹$ Cardiol 1982;49:658-64.

6 Ozaki Y, Keane D, Serruys PW. Progression and regression of coronary stenosis in longterm follow-up of vasospastic an coronary stenosis in longterm follow

7 Ozaki Y, Keane D, Haase J, et al. Temporal variability and correlation with geometric parameters in vasospastic correlation with geometric parameters in vasospastic angina: a quantit

8 Bertrand ME, Lablanche JM, Fourrier JL, Gommeaux A, Ruel $M$. Relation to restenosis after percutaneous transluminal coronary angioplasty to vasomotion of the dista coronary artery segment. Am f Cardiol 1989;63:277-81.

9 McFadden EP, Bauters C, Lablanche JM, Quandalle P, Leroy F, Bertrand ME. Response of human coronary artery to serotonin after injury by coronary angioplasty. Circulation 1993;88:2076-85.

10 Vanhoutte PM, Shimokawa H. Endothelium-derived relaxing factor and coronary vasospasm. Circulation 1989 80:1-9.

11 Ganz P, Alexander W. New insights into the cellular mechanisms of vasospasm. Am F Cardiol 1985;56:11-5E.

12 Heistrad DD, Armstrong ML, Marcus ML, Piegors DJ Mark AL. Augmented responses to vasoconstrictor stimul 
in hypercholesterolemic and atherosclerotic monkeys. Circ Res 1984;61:711-8.

13 Yasue $\mathrm{H}$, Touyama $M$, Shimamoto $M$, Kato $H$, Tanaka $S$, Akiyama F. Role of autonomic nervous system in the pathogenesis of Prinzmetal's variant form of angina. pathogenesis of Prinzmetal

14 Bassenge E. Flow-dependent regulation of coronary vasomotor tone. Eur Heart f 1989;10(suppl F):22-7.

15 Hess OM, Bortone K, Eid K, et al. Coronary vasomotor tone during static and dynamic exercise. Eur Heart $f$ 1989;10(suppl F):105-10.

16 Heusch G, Guth BD. Neurogenic regulation of coronary vasomotor tone. Eur Heart f 1989;10 (suppl F):6-14

17 Hill JA, Feldman RL, Pepine CJ, Conti CR. Regional coronary artery dilatation response in variant angina. $A m$ Heart $\mathcal{F} 1982 ; 104: 226-33$.

18 Hackett D, Larkin S, Chierchia S, Davies G, Kaski JC, Maseri A. Induction of coronary artery spasm by a direct local action of ergonovine. Circulation 1987;75:577-82.

19 Hoshino A, Kotake H, Mashiba H. Significance of coronary artery tone in patients with vasospastic angina. $\mathcal{f} \mathrm{Am}$
Coll Cardiol $1989 ; 14: 604-9$.

20 Kaski JC, Maseri A, Vejar M, Crea F, Hackett D, Halson P. Spontaneous coronary artery spasm in variant angina $\mathrm{P}$. Spontaneous coronary artery spasm in variant angina
is caused by a local hyperreactivity to a generalized is caused by a local hyperreactivity to a generalized constrictor

21 Kaski JC, Tousoulis D, Gavrielides S, et al. Comparison of epicardial coronary artery tone and reactivity in Prinzmetal's variant angina and chronic stable angina pectoris. F Am Coll Cardiol 1991;17:1058-62.

22 Kuga $T$, Egashira $K$, Inou T, Takeshita A. Correlation of basal coronary artery tone with constrictive response to ergonovine in patients with variant angina. $\mathcal{f} \mathrm{Am} C \mathrm{Coll}$ Cardiol 1993;22:144-50.

23 Schroeder JS, Bolen JL, Quint RA, et al. Provocation of coronary spasm with ergonovine maleate. New test with results in 57 patients undergoing coronary angiography. Am $\mathcal{F}$ Cardiol 1977;40:487-91.

24 Heupler FA, Proudfit WL, Razavi M, Shirey EK, Greenstreet R, Sheldon WC. Ergonovine maleate provocative test for coronary arterial spasm. Am f Cardiol 1978;41:631-40.

25 Waters DD, Szlachwic J, Theroux P, Dauwe F, Mizgala HF. Ergonovine testing to detect spontaneous remission of variant angina during long-term treatment with of variant angina during long-term treatment with
calcium antagonist drugs. Am $f$ Cardiol 1981;47: calcium

26 Previtali M, Panciroli C, Ponti RD, Chimienti M, Montemartini C, Salerno JA. Time-related decrease in sensitivity to ergonovine in patients with variant angina. Am Heart f 1989;117:92-9.

27 Lablanche JM, Leroy F, McFadden EP, Bauter C, Bertrand ME. Dose-response curve of angiographically smooth human epicardial vessel segments to intracoronary injections of isosorbide dinitrate. $\mathcal{f}$ Cardiovasc Pharmacol 1992;20:473-8.

28 Lablanche JM, Delforge MR, Tilmant PY, Thieuleux FA, Bertrand ME. Effets hémodynamiques et coronaires du dinitrate d'isosorbide; comparison entre les voies d'injection intracoronaire et intravéineuse. Arch Mal Coeur 1982;75:303-15.

29 Haase J, Escaned J, van Swijndregt EM, et al. Experimental validation of geometric and densitometric coronary measurements on the new generation cardiovascular angiography analysis system (CAAS II). Cathet Cardiovasc Diagn 1993;30:104-14

30 Serruys PW, Luyten HE, Beatt KJ, et al. Incidence of restenosis after successful coronary angioplasty: a timerelated phenomenon; a quantitative angiographic study in 342 consecutive patients at $1,2,3$, and 4 months. Circulation 1988;77:361-71

31 Ozaki Y, Keane D, Herrman JP, et al. Coronary arteriography for quantitative analysis: an experimental and clinical comparison of cinefilm and video recordings. Am Heart $\mathcal{f}$ 1995;129:471-5.

32 Ozaki Y, Keane D, Nobuyoshi M, Hamasaki N, Popma JJ, Serruys PW. Coronary lumen at 6 month follow-up of the new radiopaque tantalum stent using quantitative angiography and intracoronary ultrasound. $\mathrm{Am} \mathcal{f}$ Cardiol

33 Keane D, Haase J, Slager CJ, et al. Comparative validation of quantitative coronary angiographic systems. Results and implications from a multicenter study. Circulation 1995; 91:2174-83.

34 Keane D, Serruys PW. Quantitative coronary angiography: an integral component of interventional cardiology. In: Topol EJ, Serruys PW, eds. Current review of interventional cardiology, 2nd ed. Philadelphia: Current Medicine 1995:205-33.

35 American Heart Association Committee Report. A reporting system on patients evaluated for coronary artery disease. Circulation 1975;51:7-34.

36 Feldman RL, Pepine CJ, Curry RC, Conti CR. Coronary artery response to graded dose of nitroglycerin. $A m$ f

ost S, Bossaller C, Reil GH, et al. Reproducible uniform coronary vasomotor tone with nitrocompounds: prerequisite of quantitative coronary angiographic trials. Cathet

38 Waters DD, Szlachcic J, Bonan R, Miller DD, Dauwe F, Theroux P. Comparative sensitivity of exercise, cold pressor and ergonovine testing in provoking attacks of variant angina in patients with active disease. Circulation 1983;67:310-5.

39 Kaski JC, Crea F, Meran D, et al. Local coronary supersensitivity to diverse vasoconstrictive stimuli in patients with variant angina. Circulation 1986;74:1255-65. 